\title{
Swedish Medical Products Agency publishes report from a case inventory study on Pandemrix vaccination and development of narcolepsy with cataplexy
}

Citation style for this article:

Swedish Medical Products Agency publishes report from a case inventory study on Pandemrix vaccination and development of narcolepsy with cataplexy.

Euro Surveill. 2011;16(26):pii=19904. Available online: http://www.eurosurveillance.org/ViewArticle.aspx?Articleld=19904

On 30 June 2011 the Medical Products Agency (MPA) in Sweden published the results of a case inventory carried out by the MPA in Sweden during 2009-2010 [1]. The study presents evidence to support a link between having been vaccinated with Pandemrix and narcolepsy in children and adolescents 19 years and younger.

The case inventory study was initiated by the MPA following a large number of reports of narcolepsy among children and teenagers. The study has gathered information on severe narcolepsy cases with cataplexy (sudden and transient episode of loss of muscle tone, often triggered by emotions) from all relevant clinical departments and sleep laboratories on all suspected and established narcolepsy cases during 2009-2010. The study did not differentiate between vaccinated and un-vaccinated cases. Experts studied medical records of the cases for the purpose of verifying the narcolepsy with cataplexy diagnosis according to the American Academy of Sleep Medicine criteria for narcolepsy with cataplexy [2]. The study specifically focuses on cases in children and adolescents 19 years old and younger. Results showed that 87 cases were verified, of whom 81 were included in the study as they had onset of symptom within $\mathrm{t}$ he defined study period, 1 January 2009 to 31 December 2010. In total 69 patients (85\%) had been vaccinated with Pandemrix before onset of symptoms.

The incidence rates of narcolepsy varied by age, being around 2 per 100,000 in the 0 to 9 year age group, 3.5 in the 10 to 14 year age group and 1.7 in the 15 to 19 year age group.

Overall the incidence rate in those vaccinated was 4.2 versus 0.64 in unvaccinated per 100,000 person-years, respectively suggesting a relative risk of $6.6(95 \% \mathrm{Cl}$ $3.1-14.5)$ and an absolute risk of 3.6 (95\% confidence interval 2.5 - 4.7) additional cases per 100,000 vaccinated cases or 1 case per 27,800 vaccinations (from 1 per 40,000 to 21,300 vaccination).
References

1. Occurrence of narcolepsy with cataplexy among children and adolescents in relation to the $\mathrm{H}_{1} \mathrm{~N}_{1}$ pandemic and Pandemrix vaccinations - Results of a case inventory study by the MPA in Sweden during 2009-2010. Available from: http://www.lakemedelsverket.se/upload/nyheter/2011/ Fallinventeringsrapport_pandermrix_110630.pdf

2. American Academy of Sleep Medicine. International classification of sleep disorders, 2nd ed: Diagnostic and coding manual, American Academy of Sleep Medicine, Westchester, IL 2005. Available from: http://www.esst.org/ adds/ICSD.pdf 